\title{
Epidemiology and clonality of carbapenem-resistant Acinetobacter baumannii from an intensive care unit in Palermo, Italy
}

\author{
Caterina Mammina ${ }^{*}$, Daniela Maria Palma ${ }^{2}$, Celestino Bonura ${ }^{3}$, Aurora Aleo ${ }^{1}$, Teresa Fasciana ${ }^{3}$, Concetta Sodano $^{4}$, \\ Maria Antonietta Saporito ${ }^{4}$, Maria Stella Verde ${ }^{4}$, Cinzia Calà ${ }^{3}$, Andrea Neville Cracchiolo ${ }^{2}$ and Romano Tetamo ${ }^{2}$
}

\begin{abstract}
Background: Multidrug-resistant Acinetobacter baumannii, initially considered as having a poor clinical relevance, is frequently isolated from infection cases in intensive care units. We describe the epidemiology of carbapenem resistant A. baumannii (CRAB) in a general ICU in Palermo, Italy, from October 2010 to March 2011.

Findings: 58 of 61 isolates exhibited MICs for meropenem or imipenem $\geq 16 \mathrm{mg} / \mathrm{L}$. Forty-nine carried bla $a_{\mathrm{OXA}-23}$ and two bla OXA-58 genes.

Five subtype clusters were detected by rep-PCR. Clusters D and E included 10 isolates that tested negative for the carbapenem resistance genes. MLST attributed all isolates, but two, with sequence type (ST)2, whereas the two remaining isolates with ST78.

The respiratory tract was the most common site of infection (26 out of 36 cases. $72.2 \%$ ). A high infection related mortality rate was observed (18 out of 35 patients, 51.4\%). Nineteen patients tested positive for other multidrug resistant organisms in addition to CRAB. In eight cases isolates belonging to distinct subtype clusters and/or with distinct carbapenemase profiles were identified.

Conclusions: Carbapenem resistance was prominently driven by the dissemination of CRAB isolates belonging to

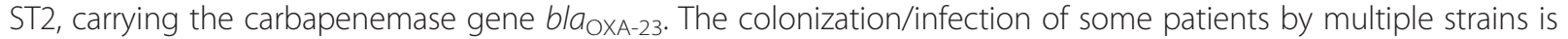
suggestive of an endemic circulation of CRAB.
\end{abstract}

\section{Findings}

Eighty-four consecutive CRAB isolates were recovered from 36 patients, who were admitted to the ICU under study between October 1, 2010 and March 31, 2011.

Based upon the inclusion criteria, 61 isolates were submitted to testing by PCR analysis to confirm the presence of carbapenemase genetic determinants and molecular typing by rep-PCR and, for representative isolates, by MLST. A number of isolates from each patient ranging between one and six was analyzed. The clinical samples more prevalent were bronchial aspirates (n. 29), followed by swabs from wound or tracheostomy (n. 8), blood (n. 7), drainage fluids and tips of central venous catheter (n. 6 each).

\footnotetext{
* Correspondence: caterina.mammina@unipa.it

'Department of Sciences for Health Promotion "G. D'Alessandro", Section of Hygiene, University of Palermo, Palermo, Italy

Full list of author information is available at the end of the article
}

Among the 61 isolates, all (100\%) were resistant to penicillins (ampicillin, carbenicillin), cephalosporins (cefepime, cefotaxime, ceftazidime), $\beta$-lactam- $\beta$-lactamase inhibitor combinations and fluoroquinolones, whereas susceptibility to aminoglycosides [amikacin, four (6.5\%) susceptible and two (3.3\%) intermediate; gentamicin, one (1.6\%) susceptible and nine (14.7\%) intermediate; tobramicin, six (9.8\%) susceptible and 12 (19.7\%) intermediate) and sulfamethoxazole-trimethoprim, nine (14.7\%) susceptible] was variable. Moreover, 50 (82.0\%) and 11 isolates (18.0\%) tested, respectively, susceptible (MICs $0.5-2 \mathrm{mg} / \mathrm{L}$ ) and intermediate (MIC $4 \mathrm{mg} / \mathrm{L}$ ) to tigecycline. Only colistin showed $100 \%$ susceptibility with MICs ranging between 0.5 and $2 \mathrm{mg} / \mathrm{L}$. Three strains only had a MIC for imipenem of $8 \mathrm{mg} / \mathrm{L}$, whilst all the remaining isolates exhibited MICs $\geq 16 \mathrm{mg} / \mathrm{L}$. Moreover, MICs for meropenem were $\geq 16 \mathrm{mg} / \mathrm{L}$ for all, but three strains that showed MICs of 4 and $8 \mathrm{mg} / \mathrm{L}$ in one and two cases, respectively. 
The 61 CRAB strains were investigated for the presence of carbapenemase genes. All isolates harboured a $b l a_{\mathrm{OXA}-51-\text { like }}$ sequence. Forty-nine isolates had, in addition, $b l a_{\text {OXA-23 }}$ and two only bla $a_{\text {OXA-58 }}$ genes. No MBL (IMP and VIM) gene sequence was detected. The two OXA-58 isolates had MICs for imipenem $\geq 16 \mathrm{mg} / \mathrm{L}$, whereas for meropenem of 4 and $8 \mathrm{mg} / \mathrm{L}$, respectively. Ten isolates for which the imipenem $\mathrm{MIC}$ was $\geq 8 \mathrm{mg} / \mathrm{L}$ had an unidentified carbapenem resistance mechanism. All tested negative for the $b l a_{\text {OXA-143 }}$ sequence. Presence of ISAba1 in the promoter region of the bla $a_{\text {OXA-51-like }}$ gene was not investigated because of the inconsistent literature findings about its correlation with carbapenem resistance and the possible involvement of alternative mechanisms [1,2].

By adopting a similarity coefficient of $\geq 95 \%$ as the threshold, all isolates, but one, clustered into five distinct groups named A to E (Fig.1). Thirty-one out of 61 clustered in a large group that included $29 b l a_{\text {OXA-23 }}$ and the two bla $a_{\text {OxA58 }}$ isolates. Two further subtype clusters, $\mathrm{B}$ and $\mathrm{C}$, included 6 and 13 OXA-23 producing isolates, respectively. Strains belonging to the subtype clusters A, $\mathrm{B}$ and C clustered at a $94 \%$ similarity level. Cluster D and cluster $\mathrm{E}$ grouped eight and two isolates, respectively, that tested negative for the carbapenem resistance genes under investigation. One isolate only did not cluster.

MLST attributed all isolates, but two, with sequence type (ST)2, whereas the two remaining isolates belonged to ST78.

There was not apparent relationship between subtype clusters, carbapenem resistance genes and the whole resistance patterns or carbapenem resistance phenotype. Twelve out of 14 isolates showing susceptibility or intermediate susceptibility to at least one aminoglycoside were isolated in the first three months of the investigation.

The main demographic and clinic characteristics of the 36 patients are summarized in Table 1 . The respiratory tract was the most common site of infection (26 out of 36 cases, 72.2\%). Moreover, a high infection related mortality rate was observed (18 out of 35 patients with a known outcome, 51.4\%). From 19 patients other MDR organisms in addition to CRAB were isolated from at least one clinical sample (Table 1). Of special interest, eight patients were co-colonized or co-infected at the same site of CRAB by Klebsiella pneumoniae carbapenemaseproducing Klebsiella pneumoniae (KPC-Kp).

From 19 out of 36 patients two to six CRAB isolates were consecutively identified in the period under study. In 11 patients an indistinguishable CRAB isolate was repeatedly identified, unlike from the remaining eight patients. In particular, three out of these patients yielded isolates belonging to distinct subtype clusters and/or



with distinct carbapenemase profiles in different clinical samples obtained up to 24 hours apart from each other; alternatively, distinct isolates were sequentially identified from the same or different clinical samples from five further patients within intervals of time ranging between four and seventy days (Table 2).

\section{Background}

The emergence of multidrug-resistant Acinetobacter baumannii strains is posing severe challenges in many clinical and post-acute care settings [3,4]. Initially considered as a colonizing bacterial species with poor clinical relevance, it is being isolated more and more frequently, especially in the intensive care units (ICUs), as the etiological agent of serious infections, such as ventilatorassociated pneumonia (VAP), infections of bloodstream, urinary tract, central nervous system and wounds [5]. A. baumannii is typically selected by prior antimicrobial 
Table 1 Demographic and clinical characteristics of the patients admitted in the period October 1, 2010 - March 31, 2011 and infected by CRAB

\begin{tabular}{|c|c|c|c|c|c|c|c|c|}
\hline patient & $\begin{array}{l}\text { age/ } \\
\text { gender }\end{array}$ & $\begin{array}{l}\text { reason for } \\
\text { admission }\end{array}$ & $\begin{array}{l}\text { underlying } \\
\text { disease }\end{array}$ & SAPSII & $\begin{array}{l}\text { type of } \\
\text { infection }\end{array}$ & $\begin{array}{l}\text { other MDR } \\
\text { organism(s) } \\
\text { isolated }\end{array}$ & $\begin{array}{l}\text { clinical } \\
\text { picture }\end{array}$ & outcome \\
\hline 1 & $77 / M$ & thoracic trauma & hypertension & 39 & cholecystitis & none & severe sepsis & discharge \\
\hline 2 & $78 / F$ & respiratory failure & lung cancer & 31 & LRTI & none & sepsis & death \\
\hline 3 & $22 / \mathrm{F}$ & polytrauma & none & 27 & RTI & none & sepsis & discharge \\
\hline 4 & $20 / M$ & cranial trauma & none & 42 & pneumonia & KPC-Kp & severe sepsis & death \\
\hline 5 & $64 / M$ & AMI & hypertension & 54 & pneumonia & KPC-Kp & septic shock & death \\
\hline 6 & $32 / F$ & $\begin{array}{l}\text { respiratory } \\
\text { failure }\end{array}$ & $\begin{array}{l}\text { major haematological } \\
\text { disease }\end{array}$ & 30 & pneumonia & none & septic shock & death \\
\hline 7 & $34 / F$ & polytrauma & none & 45 & LRTI & $\begin{array}{l}P . \\
\text { aeruginosa }\end{array}$ & sepsis & discharge \\
\hline 8 & 19/M & polytrauma & none & 48 & pneumonia & $\begin{array}{l}\text { MRSA, } \\
P . \\
\text { aeruginosa }\end{array}$ & severe sepsis & discharge \\
\hline 9 & $73 / \mathrm{M}$ & acute abdomen & $\begin{array}{l}\text { hypertension, } \\
\text { diabetes }\end{array}$ & 38 & peritonitis & KPC-Kp & septic shock & death \\
\hline 10 & $50 / \mathrm{M}$ & polytrauma & none & 44 & pneumonia & none & severe sepsis & discharge \\
\hline 11 & $74 / F$ & respiratory failure & $\begin{array}{l}\text { diabetes, } \\
\text { haematological } \\
\text { malignancy }\end{array}$ & 92 & pneumonia & $\begin{array}{l}P \text {. } \\
\text { aeruginosa }\end{array}$ & septic shock & death \\
\hline 12 & $73 / F$ & $\begin{array}{l}\text { post-surgical } \\
\text { admission }\end{array}$ & $\begin{array}{l}\text { hypertension, } \\
\text { diabetes, COPD }\end{array}$ & 18 & $\begin{array}{l}\text { complicated } \\
\text { SSTI }\end{array}$ & KPC-Kp & sepsis & discharge \\
\hline 13 & $64 / M$ & $\begin{array}{l}\text { severe } \\
\text { metabolic } \\
\text { imbalance }\end{array}$ & diabetes & 71 & pneumonia & $\begin{array}{l}P . \\
\text { aeruginosa }\end{array}$ & septic shock & death \\
\hline 14 & $39 / F$ & respiratory failure & $\begin{array}{l}\text { autoimmune } \\
\text { disease, HCV }\end{array}$ & 37 & pneumonia & ESBL-Kp & septic shock & death \\
\hline 15 & $60 / M$ & polytrauma & hypertension & 26 & pancreatitis & KPC-Kp & septic shock & death \\
\hline 16 & $60 / \mathrm{M}$ & third degree burns & hypertension & 71 & $\begin{array}{l}\text { complicated } \\
\text { SSTI }\end{array}$ & none & septic shock & death \\
\hline 17 & 70/M & encephalitis & hypertension & 50 & LRTI & KPC-Kp & severe sepsis & death \\
\hline 18 & $75 / F$ & acute abdomen & $\begin{array}{l}\text { hypertension, } \\
\text { diabetes }\end{array}$ & 32 & peritonitis & none & u.i. & u.i. \\
\hline 19 & $35 / F$ & polytrauma & none & 31 & LRTI & MRSA & sepsis & discharge \\
\hline 20 & $71 / \mathrm{M}$ & stroke & $\begin{array}{l}\text { hypertension, } \\
\text { cerebral } \\
\text { vasculopathy }\end{array}$ & 48 & pneumonia & none & severe sepsis & discharge \\
\hline 21 & 69/M & AMI & $\begin{array}{l}\text { hypertension, } \\
\text { arrhythmia }\end{array}$ & 56 & pneumonia & none & septic shock & death \\
\hline 22 & $60 / M$ & metabolic coma & hepatopathy & 71 & LRTI & none & severe sepsis & death \\
\hline 23 & $76 / F$ & respiratory failure & COPD, diabetes & 48 & pneumonia & none & septic shock & death \\
\hline 24 & $64 / \mathrm{M}$ & $\begin{array}{l}\text { post-surgical } \\
\text { admission }\end{array}$ & basalioma & 21 & $\begin{array}{l}\text { complicated } \\
\text { SSTI }\end{array}$ & $\begin{array}{l}\text { KPC-Kp, } \\
\text { ESBL-EC }\end{array}$ & cardiac arrest & death \\
\hline 25 & $68 / M$ & $\begin{array}{l}\text { post-surgical } \\
\text { admission }\end{array}$ & $\begin{array}{l}\text { autoimmune } \\
\text { disease, COPD, } \\
\text { arrhythmia }\end{array}$ & 43 & pneumonia & none & severe sepsis & discharge \\
\hline 26 & $23 / M$ & polytrauma & none & u.i. & BSI & none & septic shock & death \\
\hline 27 & 18/M & polytrauma & none & 30 & LRTI & KPC-Kp & sepsis & discharge \\
\hline 28 & $20 / F$ & respiratory failure & SLE & u.i. & cystitis & MRSE & sepsis & discharge \\
\hline 29 & $16 / \mathrm{M}$ & cranial trauma & epilepsy & u.i. & sinusitis & none & sepsis & discharge \\
\hline
\end{tabular}


Table 1 Demographic and clinical characteristics of the patients admitted in the period October 1, 2010 - March 31, 2011 and infected by CRAB (Continued)

\begin{tabular}{|c|c|c|c|c|c|c|c|c|}
\hline 30 & $70 / \mathrm{M}$ & ruptured aneurism & $\begin{array}{l}\text { hypertension, } \\
\text { COPD, } \\
\text { diabetes }\end{array}$ & 23 & LRTI & $\begin{array}{l}P . \\
\text { aeruginosa }\end{array}$ & severe sepsis & discharge \\
\hline 31 & $28 / M$ & polytrauma & none & 17 & LRTI & $\begin{array}{l}P . \\
\text { aeruginosa }\end{array}$ & sepsis & discharge \\
\hline 32 & 75/M & respiratory failure & $\begin{array}{l}\text { hypertension, } \\
\text { diabetes, CKD }\end{array}$ & 27 & pneumonia & none & septic shock & death \\
\hline 33 & $58 / \mathrm{M}$ & respiratory failure & $\begin{array}{l}\text { hypertension, } \\
\text { COPD, } \\
\text { hearth failure }\end{array}$ & 34 & pneumonia & none & severe sepsis & discharge \\
\hline 34 & $41 / \mathrm{M}$ & polytrauma & none & 38 & LRTI & MRSA & severe sepsis & discharge \\
\hline 35 & $87 / F$ & acute abdomen & coagulopathy & 45 & pneumonia & none & severe sepsis & discharge \\
\hline 35 & 64/M & metabolic coma & diabetes & 71 & pneumonia & $P$ aeruginosa & septic shock & death \\
\hline
\end{tabular}

treatments, but in turn infections caused by this organism are difficult to treat, so leading to increasingly rely on last resort molecules, such as polymyxins and tigecycline for therapy [6]. Additionally, infections with carbapenem-resistant $A$. baumannii (CRAB) organisms may require discharged patients from acute hospitals to be further managed in long-term care facilities (LTCFs) or alternative post-acute care facilities and impose diagnostic, therapeutic and infection-control extra-costs $[7,8]$.

Isolates of $A$. baumannii carry a naturally occurring bla $a_{\text {OXA-51 }} \beta$-lactamase with a weak carbapenemase activity. Moreover, in a great proportion of isolates from different geographical areas, carbapenem resistance in $A$. baumannii is mediated by the acquisition of a class $\mathrm{B}$ or a class D carbapenem-hydrolyzing enzymes [9]. In Italy, $b l a_{\text {OXA-58 }}$ has been reported to be the most prevalent OXA type carbapenem resistance gene, but a shift towards $b l a_{\text {OXA-23 }}$ that appears to be gradually substituting $b l a_{\text {OXA-58 }}$ has been recently described [10-12]. This trend is likely to be related to the a higher carbapenemase activity of $b l a_{\text {OXA-23 }}$ than $b l a_{\text {OXA-58 }}$ that results in higher carbapenem MICs and a consequent selective advantage. However, large scale data on the prevalence of these genes throughout Italy are still scarce.

Genotypic characterization of $A$. baumannii has shown that distinct clonal lineages, the so-called European (EU) clones I, II and III, are widely spread across Europe and include strains that are usually multiresistant (MDR) and responsible for epidemic and endemic occurrence of healthcare associated colonization and infection [3].

The objective of our study was to analyze the spread and clonality of CRAB in a general ICU in Palermo, Italy, by prospectively collecting and characterizing isolates from infected patients who were being admitted to the ICU over a six-month period from October 2010 to March 2011. Medical records of patients from whom $\mathrm{CRAB}$ was isolated were also retrospectively reviewed to investigate their clinical outcomes.

\section{Methods}

\section{Setting}

The $2^{\text {nd }}$ ICU of the ARNAS "Civico \& Benfratelli" General Hospital of Palermo, Italy, is a 10-bed medicalsurgical Unit with approximately 430 admissions per year. Preexisting medical and surgical conditions are generally present in approximately $45 \%$ and $55 \%$, respectively, of all admissions. Organ failure is the leading cause of admission (70\%), followed by monitoring/weaning from mechanical ventilation (30\%). ICU mortality is about $25 \%$. Nurse to patient ratio is 1:2.

Consecutive CRAB isolates were recovered from all patients who were admitted to $2^{\text {nd }}$ Intensive ICU during the six-month period October 1, 2010 - March 31, 2011. For the purpose of this study, the following inclusion criteria were used for the selection of CRAB isolates to be submitted to molecular typing: a) all the unique isolates from different patients; b) replicate isolates obtained from different clinical samples of the same patient up to 24 hours apart from each other; c) replicate isolates obtained from the same patient more than 24 hours apart from each other from whatever clinical sample.

CRAB isolates were isolated by standard methods and identified by the Vitek 2 automated microbiology system (bioMérieux, Marcy l'Étoile, France). Antimicrobial susceptibility testing was automatically undertaken by using the commercial microdilution method Vitek 2. The 
Table 2 Source, time of isolation, carbapenem MICs and molecular characteristics of the replicate CRAB isolates from the eight patients yielding distinct isolates by subtype cluster and/or carbapenemase profile

\begin{tabular}{|c|c|c|c|c|c|c|c|c|}
\hline patient* & isolate & date of isolation & clinical sample & MIC imipenem & MIC meropenem & PCR & rep-PCR cluster & ST \\
\hline \multirow[t]{2}{*}{3} & 33 & October 13, 2010 & BA & $>=16$ & $>=16$ & OXA-23 & B & 2 \\
\hline & 18 & October 14, 2010 & CVC & $>=16$ & $>=16$ & OXA-23 & A & 2 \\
\hline \multirow[t]{3}{*}{4} & 51 & October 25, 2010 & BA & $>=16$ & $>=16$ & OXA-23 & singleton & 2 \\
\hline & 29 & December 1, 2010 & CSF & $>=16$ & $>=16$ & OXA-23 & A & 2 \\
\hline & 46 & December 28, 2010 & CSF & $>=16$ & $>=16$ & OXA-23 & C & 2 \\
\hline \multirow[t]{3}{*}{9} & 19 & November 22, 2010 & peritoneal fluid & $>=16$ & $>=16$ & OXA-23 & A & 2 \\
\hline & 32 & November 22, 2010 & BA & $>=16$ & $>=16$ & OXA-23 & B & 2 \\
\hline & 53 & November 23, 2010 & blood & $>=16$ & $>=16$ & negative & $\mathrm{D}$ & 2 \\
\hline \multirow[t]{6}{*}{15} & 13 & December 27, 2010 & BA & $>=16$ & $>=16$ & OXA-23 & A & 2 \\
\hline & 17 & January 7, 2011 & drainage fluid & $>=16$ & $>=16$ & OXA-23 & A & 2 \\
\hline & 30 & January 8, 2011 & blood & $>=16$ & $>=16$ & OXA-23 & A & 2 \\
\hline & 16 & January 19, 2011 & drainage fluid & $>=16$ & $>=16$ & OXA-23 & A & 2 \\
\hline & 14 & January 29, 2011 & wound swab & $>=16$ & $>=16$ & OXA-23 & A & 2 \\
\hline & 61 & February 14, 2011 & blood & 8 & $>=16$ & negative & E & 78 \\
\hline \multirow[t]{2}{*}{17} & 44 & January 3, 2011 & BA & $>=16$ & $>=16$ & OXA-23 & C & 2 \\
\hline & 11 & January 7, 2011 & blood & $>=16$ & $>=16$ & OXA-23 & A & 2 \\
\hline \multirow[t]{2}{*}{23} & 48 & January 24, 2011 & drainage fluid & 8 & 8 & OXA-23 & C & 2 \\
\hline & 6 & January 25, 2011 & tracheostomy swab & $>=16$ & $>=16$ & OXA-23 & A & 2 \\
\hline \multirow[t]{2}{*}{24} & 60 & January 24, 2011 & BA & $>=16$ & $>=16$ & negative & E & 78 \\
\hline & 45 & April 4, 2011 & wound swab & $>=16$ & $>=16$ & OXA-23 & A & 2 \\
\hline \multirow[t]{2}{*}{27} & 41 & February 21, 2011 & BA & $>=16$ & $>=16$ & OXA-23 & C & 2 \\
\hline & 23 & March 11, 2011 & tracheostomy swab & $>=16$ & $>=16$ & OXA-23 & A & 2 \\
\hline
\end{tabular}

* patient's numeric code refers to Table 1 .

BA, bronchial aspirate; CVC, central venous catheter; CSF, cerebrospinal fluid.

MICs of imipenem and meropenem were determined by using the epsilometer test (Etest, AB Biodisk, Solna, Sweden). Results were interpreted according to Clinical and Laboratory Standards Institute (CLSI) criteria for Acinetobacter spp [13]. Due to the lack of standardization for A. baumannii, Enterobacteriaceae breakpoints ( $\leq 2 \mu \mathrm{g} / \mathrm{ml}$, susceptible; $\geq 8 \mu \mathrm{g} / \mathrm{ml}$, resistant) were used for interpreting the results of the tigecycline assays. The control strain used was Escherichia coli ATCC 25922.

\section{Characterization of CRAB isolates}

To detect the presence of the most common carbapenemases, multiplex PCR was performed with primers that anneal to $b l a_{\mathrm{OXA}-51}, b l a_{\mathrm{OXA}-23}, b l a_{\mathrm{OXA}-24}$ and $b l a_{\mathrm{OXA}-58}$ carbapenemases and the MBLs $b a_{\mathrm{IMP}}$ and $b l a_{\mathrm{VIM}}$, as previously described $[14,15]$.

The newly described gene $b l a_{\text {OXA-143 }}$ was also searched for [16].

To investigate the relationship among the CRAB isolates collected during the study period, we used the repPCR DiversiLab Microbial Typing System ${ }^{\circledR}$ (bioMérieux, Marcy l'Étoile, France), which amplifies the regions between the non-coding repetitive sequences in bacterial genomes. Extraction of DNA was performed using the UltraCleanTM Microbial DNA Isolation Kit (Mo Bio Laboratories, Inc., Carlsbad, CA, USA). Rep-PCR was performed using the DiversiLab Acinetobacter kit. DNA fragment separation and detection were done using the Agilent 2100 Bioanalyzer (Agilent Technologies, Santa Clara, CA, USA) and results were analyzed and interpreted using the Kullback-Leibler method, as previously reported [17]. Isolates were defined as genetically related when $\geq 95 \%$ similarity was identified.

Genotyping by multilocus sequence typing (MLST) was performed on representative CRAB strains selected on the basis of clustering by rep-PCR and carbapenemase gene pattern. MLST was based on the sequence analysis of the internal portions of seven housekeeping genes (cpn60, fus $\mathrm{A}, g l t \mathrm{~A}, p y r \mathrm{G}, r e c \mathrm{~A}, r p l \mathrm{~B}$ and $r p o \mathrm{~B})$. All PCR amplifications were carried out under the following conditions: 30 cycles (denaturation at $94{ }^{\circ} \mathrm{C}$ for $1 \mathrm{~min}$, annealing at $53{ }^{\circ} \mathrm{C}$ for $1 \mathrm{~min}$, and extension at $72{ }^{\circ} \mathrm{C}$ for $1 \mathrm{~min}$ ) preceded by a 5 -min denaturation at $94{ }^{\circ} \mathrm{C}$ and followed by a 10 -min extension at $72{ }^{\circ} \mathrm{C}$. PCR products were sequenced in both directions by using BigDye fluorescent terminators and primers on a 310 DNA 
analyzer (Applied Biosystems, Warrington, United Kingdom). Details of the MLST scheme including amplification and sequencing primers, allele sequences and STs are available at Institute Pasteur's MLST Web site (www.pasteur.fr/mlst).

\section{Patients characteristics}

The medical records of patients from whom CRAB was isolated were retrospectively reviewed. The following demographic and clinical data were obtained: age, gender, reason for admission, underlying diseases, type of infection and clinical manifestation, Mean Simplified Acute Physiology Score II (SAPS II), isolation of other MDR organisms, such as ESBL producing enterobacteria, vancomycin-resistant Enterococcus spp. (VRE) and methicillin-resistant Staphylococcus aureus (MRSA), if any, and outcome (dead/discharged).

This research conformed to local legislation and the Helsinki Declaration and was approved by the ethics committee of the ARNAS General Hospital "Civico \& Benfratelli, Palermo, Italy.

\section{Discussion}

CRAB is an healthcare serious issue in many European countries. Literature shows that carbapenem resistance rates are higher in southern Europe countries, such as Turkey, Greece, Spain and Italy [18]. In Europe, outbreaks are especially attributable to two main $A$. baumannii clones (the so-called European clones I and II) [19]. Clone II has been repeatedly reported in many European countries, including Italy [5,8-10]. With regard to the mechanism of carbapenem resistance in the Italian CRAB isolates, the spread of carbapenemases belonging to the molecular class D OXA enzymes has been well documented [8-10,19-22].

Our study reveals that carbapenem resistance in the ICU under study was prominently driven by the dissemination of CRAB isolates belonging to ST2, the European clone II, carrying the carbapenemase gene bla $a_{\text {OXA-23 }}$. Of interest, in comparison with the data obtained by previous studies conducted in Italy, as well also in other Mediterranean countries, the prevalence of $b l a_{\text {OXA-58 }}$ carrying isolates appears to be drastically lower [10,21,22]. Emergence of an epidemic lineage carrying $b l a_{\text {OXA-23 }}$ carbapenemase genes that is displacing a genetically closely related CRAB clone encoding OXA-58 has been previously described in central Italy in a study involving 10 ICU [8]. The higher level resistance to carbapenems conferred by OXA-23 is thought to be the success key of OXA-23 carrying epidemic strains under the selective pressure due to the increasing use of carbapenems, mainly in combination with fluoroquinolones, forced in turn by the epidemic spread of extended spectrum $\beta$ lactamase producing organisms [23].
Five subtype clusters were recognized by rep-PCR typing, with the first three - A to $\mathrm{C}$ - appearing to be closely related and all belonging to ST2, so suggesting the dissemination in the ICU of at least three well differentiated clones. Isolates belonging to two of them, D and $\mathrm{E}$, tested negative for carbapenemase genes under study, except for bla OxA-51-like. The two isolates belonging to the subtype cluster E were attributed with ST78, the so called "Italian clone". This clone, after being identified firstly in Naples, Italy, in 2006-2007 as an emerging epidemic clone, has been subsequently identified in other cities of southern Italy, Catania, and northern, Italy, Novara, accounting for a $13 \%$ proportion of isolates [10,20-22]. More recently, the same clone has been detected in ICUs, but also in home-care patients in $\mathrm{Pa}$ lermo, Italy [5]. Hence, ST78 seems to have largely disseminated in Italy [20-22].

The detection in a same patient of CRAB isolates belonging to different subtype clusters is a concerning finding. An underestimation of the event is very likely due to the routinely adopted microbiological diagnostic procedures, that are not aimed at detecting a mixed population of CRAB in patient or a clinical sample. Furthermore, because an active culture surveillance program was not in place in the ICU under study, prevalence of $C R A B$ positive patients/sites is likely to be much higher and the relative proportion of the different strains misrepresented. Nevertheless, identification of distinct strains in an interval of time of 24 hours strongly suggests that some patients could be simultaneously or sequentially colonized or infected by multiple strains. The clinical and prognostic significance of such a finding deserves further investigation. The variety of subtype clusters could be likely interpreted as suggestive of a situation of endemicity where the selective advantage conferred by the high level carbapenem resistance supports the epidemic spread of the ST2 lineage carrying the bla $a_{\text {OXA-23 }}$ determinant.

According with previous Authors, our data confirm that $C R A B$ is one of the most challenging Gramnegative pathogens to control and treat in the ICUs, resulting in serious infections and substantial mortality [24,25]. Unfortunately, infection control measures used to contain the CRAB dissemination can be very difficult to be applied and substantially ineffective when it has become endemic. On the other hand, compelling evidence has accumulated about the contribution that contaminated surfaces make to the epidemic and endemic transmission of many MDR organisms and above all CRAB and MRSA [26,27].

\section{Conclusions}

Spread in the healthcare settings of CRAB is posing extremely challenging questions about the most effective 
strategies to be adopted in the infected patient management as well as in the control and prevention of transmission within and between the healthcare facilities. A timely recognition and an accurate description of the CRAB strains and clones that are spreading in a defined area can contribute to obtain a more reliable epidemiological picture and to devise effective and targeted control measures.

\section{Abbreviations \\ CRAB: Carbapenem resistant $A$. baumannii; ICU: Intensive care unit; LTCF: Long term care facility; MDR: Multidrug resistant; MIC: Minimum inhibitory concentration; MLST: MultiLocus sequence typing; rep- PCR: Repetitive sequence polymerase chain reaction; ST: Sequence type; VAP: Ventilator-associated pneumonia.}

\section{Competing interests}

The authors declare that they have no competing interests.

\section{Acknowledgments}

We would like to thank all the personnel of the Laboratory of microbiology and the II Intensive Care Unit of the ARNAS General Hospital "Civico \& Benfratelli, Palermo, Italy, for their helpful contribution in collecting microbiological, epidemiological and clinical data.

\section{Author details}

'Department of Sciences for Health Promotion "G. D'Alessandro", Section of Hygiene, University of Palermo, Palermo, Italy. ${ }^{2}$ II Intensive Care Unit, ARNAS General Hospital "Civico \& Benfratelli, Palermo, Italy. ${ }^{3}$ Department of Sciences for Health Promotion "G. D'Alessandro", Section of Microbiology, University of Palermo, Palermo, Italy. ${ }^{4}$ Laboratory of Microbiology, ARNAS General Hospital "Civico \& Benfratelli, Palermo, Italy.

\section{Authors' contributions}

CM and DMP designed the study. CS, MAS and MSV were in charge of identify and collect strains and information about them. CB, AA,TF and CC carried out typing of isolates and characterization of resistance genetic determinants. DMP, ANC and RT provided the clinical data about patients. CM, DMP, CB and ANC analyzed the data and wrote the paper. RT supervised the study. All authors read and approved the final manuscript.

Received: 22 March 2012 Accepted: 20 July 2012

Published: 20 July 2012

\section{References}

1. Tsakris A, Ikonomidis A, Poulou A, Spanakis N, Vrizas D, Diomidous M, Pournaras S, Markou F: Clusters of imipenem-resistant Acinetobacter baumannii clones producing different carbapenemases in an intensive care unit. Clin Microbiol Infect 2008, 14:588-594.

2. Bratu S, Landman D, Martin DA, Georgescu C, Quale J: Correlation of antimicrobial resistance with $\beta$-lactamases, the OmpA-like porin, and efflux pumps in clinical isolates of Acinetobacter baumannii endemic to New York City. Antimicrob Agents Chemother 2008, 52:2999-3005.

3. Higgins PG, Dammhayn C, Hackel M, Seifert H: Global spread of carbapenem-resistant Acinetobacter baumannii. J Antimicrob Chemother 2010, 65:233-238.

4. Orsi GB, Falcone M, Venditti M: Surveillance and management of multidrug-resistant microorganisms. Expert Rev Anti Infect Ther 2011, 9:653-679.

5. Dijkshoorn L, Nemec A, Seifert H: An increasing threat in hospitals: multidrug-resistant Acinetobacter baumannii. Nat Rev Microbiol 2007, 5:939-951

6. Vila J, Pachón J: Acinetobacter baumannii resistant to everything: what should we do? Clin Microbiol Infect 2011, 17:955-956.

7. Mammina C, Bonura C, Aleo A, Calà C, Caputo G, Cataldo MC, Di Benedetto A, Distefano S, Fasciana T, Labisi M, Sodano C, Palma DM, Giammanco A: Characterization of Acinetobacter baumannii from intensive care units and home care patients in Palermo, Italy. Clin Microbiol Infect 2011, 17:E12-15.
8. Sengstock DM, Thyagarajan R, Apalara J, Mira A, Chopra T, Kaye KS: Multidrug-resistant Acinetobacter baumannii: an emerging pathogen among older adults in community hospitals and nursing homes. Clin Infect Dis 2010, 50:1611-1616.

9. Pfeifer Y, Cullik A, Witte W: Resistance to cephalosporins and carbapenems in Gram-negative bacterial pathogens. Int J Med Microbiol 2010, 300:371-379

10. D'Arezzo S, Principe L, Capone A, Petrosillo N, Petrucca A, Visca P: Changing carbapenemase gene pattern in an epidemic multidrug-resistant Acinetobacter baumannii lineage causing multiple outbreaks in central Italy. J Antimicrob Chemother 2011, 66:54-61.

11. Mendes RE, Spanu T, Deshpande L, Castanheira M, Jones RN, Fadda G: Clonal dissemination of two clusters of Acinetobacter baumannii producing OXA-23 or OXA-58 in Rome, Italy. Clin Microbiol Infect 2009, 15:588-592.

12. Mezzatesta ML, D'Andrea MM, Migliavacca R, Giani T, Gona F, Nucleo E, Fugazza G, Pagani L, Rossolini GM, Stefani S: Epidemiological characterization and distribution of carbapenem-resistant Acinetobacter baumannii clinical isolates in Italy. Clin Microbiol Infect 2011, doi:10.1111/ j.1469-0691.2011.03527.x.

13. Clinical and Laboratory Standards Institute (CLSI): Performance standards for antimicrobial susceptibility testing. Twentieth informational supplement M100-S20. Wayne, PA: Clinical and Laboratory Standards Institute; 2010.

14. Woodford N, Ellington MJ, Coelho JM, Turton JF, Ward ME, Brown S, Amyes SG, Livermore DM: Multiplex PCR for genes encoding prevalent OXA carbapenemases in Acinetobacter spp. Int J Antimicrob Agents 2006, 27:351-353.

15. Poirel L, Walsh TR, Cuvillier V, Nordmann P: Multiplex PCR for detection of acquired carbapenemase genes. Diagn Microbiol Infect Dis 2011, 70:119-123.

16. Higgins $P G$, Lehmann $M$, Seifert $H$ : Inclusion of OXA-143 primers in a multiplex polymerase chain reaction (PCR) for genes encoding prevalent OXA carbapenemases in Acinetobacter spp. Int J Antimicrob Agents 2010, 35:305.

17. Perez F, Endimiani A, Ray AJ, Decker BK, Wallace CJ, Hujer KM, Ecker DJ, Adams MD, Toltzis P. Dul MJ, Windau A, Bajaksouzian S, Jacobs MR, Salata RA, Bonomo RA: Carbapenem-resistant Acinetobacter baumannii and Klebsiella pneumoniae across a hospital system: impact of post-acute care facilities on dissemination. J Antimicrob Chemother 2010, 65:1807-1818

18. Towner KJ, Levi K, Vlassiadi M: the ARPAC Steering Group: Genetic diversity of carbapenem-resistant isolates of Acinetobacter baumannii in Europe. Clin Microbiol Infect 2008, 14:161-167.

19. Ansaldi F, Canepa P, Bassetti M, Zancolli M, Molinari MP, Talamini A, Ginocchio F, Durando P, Mussap M, Orengo G, Viscoli C, Icardi G: Sequential outbreaks of multidrug-resistant Acinetobacter baumannii in intensive care units of a tertiary referral hospital in Italy: combined molecular approach for epidemiological investigation. $J$ Hosp Infect 2011 , 79:134-140

20. Giannouli M, Cuccurullo S, Crivaro V, Di Popolo A, Bernardo M, Tomasone F, Amato G, Brisse S, Triassi M, Utili R, Zarrilli R: Molecular epidemiology of multidrug-resistant Acinetobacter baumannii in a tertiary care hospital in Naples, Italy, shows the emergence of a novel epidemic clone. J Clin Microbiol 2010, 48:1223-1230.

21. Di Popolo A, Giannouli M, Triassi M, Brisse S, Zarrilli R: Molecular epidemiological investigation of multidrug-resistant Acinetobacter baumannii strains in four Mediterranean countries with a multilocus sequence typing scheme. Clin Microbiol Infect 2011, 17:197-201.

22. Carretto E, Barbarini D, Dijkshoorn L, van der Reijden TJ, Brisse S, Passet V, Farina C: APSI Acinetobacter Study Group: Widespread carbapenem resistant Acinetobacter baumannii clones in Italian hospitals revealed by a multicenter study. Infect Genet Evol 2011, 11:1319-1326.

23. Maragakis LL, Perl TM: Acinetobacter baumannii: epidemiology, antimicrobial resistance, and treatment options. Clin Infect Dis 2008, 46:1254-63.

24. Esterly JS, Griffith M, Qi C, Malczynski M, Postelnick MJ, Scheetz MH: Impact of carbapenem resistance and receipt of active antimicrobial therapy on clinical outcomes of Acinetobacter baumannii bloodstream infections. Antimicrob Agents Chemother 2011, 55:4844-4849.

25. Ye JJ, Lin HS, Kuo AJ, Leu HS, Chiang PC, Huang CT, Lee MH: The clinical implication and prognostic predictors of tigecycline treatment for 
pneumonia involving multidrug-resistant Acinetobacter baumannii.

$J$ Infect 2011, 63:351-361.

26. Otter JA, Yezli S, French GL: The role played by contaminated surfaces in the transmission of nosocomial pathogens. Infect Control Hosp Epidemiol 2011, 32:687-699.

27. Markogiannakis A, Fildisis G, Tsiplakou S, Ikonomidis A, Koutsoukou A, Pournaras S, Manolis EN, Baltopoulos G, Tsakris A: Cross-transmission of multidrug-resistant Acinetobacter baumannii clonal strains causing episodes of sepsis in a trauma intensive care unit. Infect Control Hosp Epidemiol 2008, 29:410-417.

doi:10.1186/1756-0500-5-365

Cite this article as: Mammina et al:: Epidemiology and clonality of carbapenem-resistant Acinetobacter baumannii from an intensive care unit in Palermo, Italy. BMC Research Notes 2012 5:365.

\section{Submit your next manuscript to BioMed Central and take full advantage of:}

- Convenient online submission

- Thorough peer review

- No space constraints or color figure charges

- Immediate publication on acceptance

- Inclusion in PubMed, CAS, Scopus and Google Scholar

- Research which is freely available for redistribution 